\title{
Ultrasonic characterisation of steel fibre orientation in ultra-high performance concrete
}

\author{
Benjamin Ankay $^{1}$, Kevin Metje ${ }^{2}$, Tom Mönig ${ }^{1,2}$, Chuanzeng Zhang ${ }^{1}$, Torsten Leutbecher ${ }^{2}$ \\ ${ }^{1}$ Chair of Structural Mechanics, University of Siegen, 57068 Siegen, Germany \\ ${ }^{2}$ Chair of Structural Concrete, University of Siegen, 57068 Siegen, Germany
}

\section{Summary}

Ultrasonic technology has proven to be a reliable non-destructive method for testing engineering applications. Especially for complex composites, like fibre-reinforced plastics or fibre-reinforced concrete, the pulse velocity method can be used to analyse the fibre-induced anisotropy. In the present study, ultrasonic testing was applied to investigate the fibre orientation in ultra-high performance fibrereinforced concrete (UHPFRC). UHPFRC is a composite consisting of concrete and steel fibres, which distinguishes itself from conventional concrete by higher compressive and tensile strength as well as a particularly high durability. Steel fibres influence the tensile behaviour after the formation of microcracks decisively and increase the ductility of UHPFRC members. The orientation and distribution of fibres significantly influence the bearing behaviour and are thus important parameters when designing UHPFRC members. In ultrasound experiments, the main orientation of the fibres in UHPFRC specimens was determined by a method based on analysing the wave velocities of polarised shear waves. Subsequently, the specimens were cut perpendicular and parallel to the predominant fibre alignment predicted by ultrasonic testing and the actual orientation of the fibres in the cross-sections was evaluated by an optoanalytical method. Comparison of test data suggests that the proposed ultrasonic testing method is a suitable tool for predicting the predominant fibre alignment in UHPFRC members.

Keywords: ultrasonic method, concrete, steel fibres, fibre orientation, UHPC

\section{Introduction}

\subsection{Ultrasonic testing in concrete}

Since many decades non-destructive testing using ultrasound technology has proven to be a flexible, robust, meaningful, and comparatively cost-effective method for a wide range of engineering applications. Today different standard methods for ultrasonic testing of structural components are available. Especially in the fields of aircraft construction, mechanical engineering and railway transport, many standardised methods have been developed and established. The application in these fields is related to the ultrasonic non-destructive testing of adhesive bonds, joint connections, damage detection and generally the quality control of metallic and plastic materials.

Ultrasonic testing of concrete in civil engineering applications is still relatively new and has not been widely applied compared to other engineering fields mentioned above. However, over the years several ultrasonic methods for non-destructive concrete testing have been developed and have been included in guide- lines and standards worldwide (e.g. ASTM C 597, EN 12504-4).

Basically, the major problem in ultrasonic testing of concrete is related to the highly heterogeneous structure of the material [1]. The complex meso- and microstructure of concrete, such as different aggregate sizes or voids inside the composite, leads to multiple scattering, reflections and absorption of the emitted ultrasonic waves. These factors influence the evaluation of the received ultrasonic signals considerably. Therefore, ultrasound experiments for concrete are usually carried out in the low-frequency range $(50-250 \mathrm{kHz})$ in order to achieve a smaller disturbance due to the coarse aggregate in the material and thus to obtain a high signal to noise ratio. However, it must be considered that a reduction in the frequency always results in a worse spatial resolution and thus smaller defects can no longer be detected or resolved. With progress in the development of ultrasonic sensors nowadays efficient low-frequency broadband transducers allow testing of concrete structures reliably also in the so-called pulse-echo mode [2]. In the pulse-echo mode the transducer 
acts simultaneously as a transmitter and receiver of ultrasonic waves. Here, the emitted ultrasonic pulse is reflected at a material boundary and the resulting echo is received at the transmission point. This is an improvement and a simplification for practical applications compared to the through-transmission mode [3], where the component must be accessible from both sides, which is often difficult or impossible.

As an established standard method, the pulse velocity measurement is used [1], where the required travel time of the ultrasonic pulse through the specimen is determined. From the data obtained, the pulse velocity of the tested concrete can be calculated, which can be used to assess the quality and strength of the concrete. Furthermore, damages or defects such as cracks, pores, and cavities as well as largescale inhomogeneities can be detected [1]. Similarly, pulse velocity measurements on fibre reinforced concrete (FRC) have shown the influence of the distribution, orientation, and volume fraction of steel fibres on the acoustic characteristics [4-7]. In these studies, mostly longitudinal ultrasonic waves were used to detect the change in the measured wave velocity in concrete due to different fibre volume fraction and fibre orientation.

Basically, it can be assumed that the addition of fibres influences the elastic properties (e.g. the modulus of elasticity and Poisson's ratio) of the concrete depending on the specific FRC mix design and fibre orientation. In particular, a pronounced uniaxial or two-dimensional fibre orientation leads, similar to fibre-reinforced plastics (CFRP, GFRP), to a transverse anisotropy.

\subsection{Ultrasonic testing in UHPFRC}

Ultra-high performance concrete (UHPC) [8] is a heterogeneous composite made of cement, water, quartzitic or basaltic aggregate as well as reactive and non-reactive admixtures and additives. The compressive strength of UHPC typically ranges between 150 and $200 \mathrm{~N} / \mathrm{mm}^{2}$. This high strength and a very dense microstructure are obtained by reducing the watercement ratio to typically about 0.25 and by grading the fine raw materials which provides an increased packing density. Superplasticiser is used to ensure the workability of the fresh concrete. As it is typical for concrete, the tensile strength of UHPC is low compared to its compressive strength. It typically ranges between about 7 and $11 \mathrm{~N} / \mathrm{mm}^{2}$ [8].

With increasing compressive strength the concrete becomes more brittle. To counteract this tendency and to increase the deformation capacity after appearance of cracks, steel fibres are added to the concrete mixture. So-called ultra-high performance fibre-reinforced concrete (UHPFRC) typically contains fibre volume fractions between 0.5 to $2.5 \%$ using smooth straight steel fibres with lengths of typically 9 to $25 \mathrm{~mm}$ and diameters of typically 0.10 to $0.25 \mathrm{~mm}$.

Beside increasing the UHPFRC's ductility, steel fibres enable the concrete to transfer tensile stresses through cracks and thus improve the tensile behaviour $[9,10]$ and significantly increase the bearing capacity of UHPFRC members subjected to bending, shear and/or torsion [8]. To benefit from these effects in structural design, knowledge of the specific fibre distribution and orientation inside a structural member is required $[11,12]$.

Ultrasonic testing in UHPC has been performed only occasionally so far. It has already been found that UHPC is particularly suitable for high-resolution ultrasonic testing due to its dense microstructure and comparably high homogeneity [4]. Furthermore, as shown in [4], the dynamic modulus determined by ultrasonic measurement corresponds well with the modulus of elasticity obtained from uniaxial compressive tests. For fine-grained UHPC, high testing frequencies in the range of $1 \mathrm{MHz}$ can still be used avoiding the problem mentioned above [4], since the maximum aggregate size, which is in the range of less than $1 \mathrm{~mm}$, is still below the associated wavelength, which leads to a higher resolution of the material structure. For UHPFRC the same frequency range may be used, since the fibres have no major influences on the signal to noise ratio.

A fibre-induced anisotropy has already been observed for UHPFRC specimens under static compressive loading [13]. There, various approaches considering the transverse anisotropy have been applied, which predict a variation in the elastic parameters between 5 to $10 \%$ depending on the loading direction. In [11] direct tensile tests were conducted on specimens with different fibre orientations. In this study, the modulus of elasticity also varied in the range of 5 to $10 \%$.

The magnitude of variation suggest that the anisotropy of the elastic parameters can also be detected by ultrasonic measurements using elastic waves. However, the challenge is that due to the low fibre volume fraction only a small variation in the acoustic parameters, such as the wave velocity, is to be expected. 


\section{Analytical and experimental investiga- tions}

\subsection{Analytical consideration and experi- mental procedure}

Since an absolute measurement of the acoustic parameters and its subsequent comparison is often limited by the achievable measurement accuracy, a relative ultrasonic measurement was performed in this study to capture the expected small velocity variations. Here, a pulse-echo method using polarised shear waves is applied to determine the relative pulse velocity change in a specimen while rotating the ultrasound transducer.

The use of transverse waves for ultrasonic inspection is a well-established method for determining the material anisotropy caused by the structure itself or by directional damage effects. Similar methods based on the principle of shear wave birefringence/splitting have recently been used in the field of fibre-reinforced plastics $[14,15]$ and have also been applied to anisotropic materials such as wood [16]. Generally, the anisotropy level is much larger in this kind of materials in comparison with fibrereinforced concrete. However, the presented studies show that even small changes in the material behaviour are detectable with this method. To classify the direction-dependent changes in the wave velocity present in UHP$\mathrm{FRC}$, an analytical examination based on a layer model [17] is performed (Fig. 1).

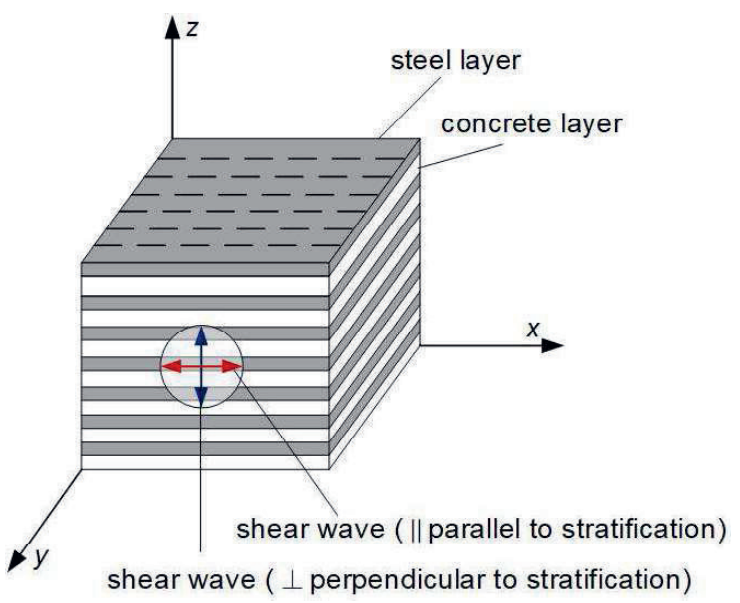

Fig. 1: Shear wave propagation in fibrereinforced concrete idealised by a layer model

According to the layer model for a shear wave with propagation direction and particle motion parallel to the stratification (but perpendicular to eachother) the corresponding wave velocity is given by Eq. (1).
$v_{\|}=\sqrt{\frac{\left(n_{\mathrm{A}} \rho_{\mathrm{A}} v_{\mathrm{A}}^{2}+n_{\mathrm{B}} \rho_{\mathrm{B}} v_{\mathrm{B}}^{2}\right)}{\left(n_{\mathrm{A}} \rho_{\mathrm{A}}+n_{\mathrm{B}} \rho_{\mathrm{B}}\right)}}$

where

$\rho: \quad$ mass density of the material

$v$ : velocity of the shear wave

$n$ : volume fraction of the material

The subscript indices denote the two materials $A$ and $B$ under consideration.

If the particle motion is perpendicular to the stratification (normal to the layer) the corresponding wave velocity is given by Eq. (2).

$$
v_{\perp}=\sqrt{\frac{1}{\left(\frac{n_{\mathrm{A}}}{\rho_{\mathrm{A}} v_{\mathrm{A}}^{2}}+\frac{n_{\mathrm{B}}}{\rho_{\mathrm{B}} v_{\mathrm{B}}^{2}}\right)\left(n_{\mathrm{A}} \rho_{\mathrm{A}}+n_{\mathrm{B}} \rho_{\mathrm{B}}\right)}}
$$

As a specific example, the material $A$ is taken as steel with a density $\rho_{\mathrm{A}}=7850 \mathrm{~kg} / \mathrm{m}^{3}$ and a shear wave velocity $V_{A}=3200 \mathrm{~m} / \mathrm{s}$, while the material $B$ is selected as UHPC with a density $\rho_{\mathrm{B}}=2400 \mathrm{~kg} / \mathrm{m}$ and a shear wave velocity $V_{B}=2900 \mathrm{~m} / \mathrm{s}$. Regarding realistic fibre volume fractions in UHPFRC the volume fraction of both materials is set to $n_{\mathrm{A}}=0.025$ and $n_{\mathrm{B}}=0.975$, which means that the volume fraction of steel in the total volume is assumed to be $2.5 \%$. This results in the following values for the corresponding shear wave velocities determined by Eqs. (3) and (4).

$$
\begin{aligned}
& v_{\|} \approx 2924 \mathrm{~m} / \mathrm{s} \\
& v_{\perp} \approx 2848 \mathrm{~m} / \mathrm{s}
\end{aligned}
$$

Therefore, the shear wave velocity with polarisation parallel to the layer results in an absolute value that is about $2.6 \%$ higher than the corresponding velocity perpendicular to the layer. This gives a good estimation on the velocity changes expected in ultrasonic experiments on UHPFRC specimens.

In order to evaluate the wave velocity change of polarised shear waves by ultrasonic experiments, the UHPFRC specimens should ideally provide a nearly uniaxial fibre orientation.

\subsection{Specimen preparation}

To provoke a predominant fibre alignment in the specimen, thin panels were cast in different arrangement ( $3 \times$ upright $/ 1 \times$ reclined) as well as with varying casting method. Previous studies demonstrated the influence of the casting method on the flow of the fresh concrete and thus on the distribution and orientation of the fibres inside the specimen $[11,18,19]$. 
For the present study, a fine-grained UHPFRC with a maximum aggregate size of $0.5 \mathrm{~mm}$ was used in order to ensure a microstructure as homogeneous as possible. The fibre volume fraction was $2.5 \%$. The steel fibres had a length of $10 \mathrm{~mm}$ and a diameter of $0.175 \mathrm{~mm}$. Tab. 1 shows the mix design.

Tab. 1: UHPFRC mix design

\begin{tabular}{lr}
\hline Cement 52,5 R & $765 \mathrm{~kg} / \mathrm{m}^{3}$ \\
Silica fume & $160 \mathrm{~kg} / \mathrm{m}^{3}$ \\
Quartz flour 0/0.125 mm & $195 \mathrm{~kg} / \mathrm{m}^{3}$ \\
Quartz sand 0.125/0.5 mm & $950 \mathrm{~kg} / \mathrm{m}^{3}$ \\
Superplasticiser (30\% solids) & $26 \mathrm{~kg} / \mathrm{m}^{3}$ \\
Steel fibres $10 / 0.175 \mathrm{~mm}$ & $196 \mathrm{~kg} / \mathrm{m}^{3}$ \\
Water & $195 \mathrm{~kg} / \mathrm{m}^{3}$ \\
Water-cement ratio & $0.28^{*}$ \\
\hline * Taking into account the water content of the \\
superplasticiser
\end{tabular}

The panels were about $450 \mathrm{~mm}$ high, $1200 \mathrm{~mm}$ long and $40 \mathrm{~mm}$ thick. The concrete was poured from one end. The mould of the three vertically cast panels was inclined by an angle of $63^{\circ}$ at the end where the concrete was poured into the mould in order to ensure a steady flow velocity (Fig. 2a). The mould of the horizontally cast panel was inclined by an angle of about $4^{\circ}$ with regard to the horizontal (Fig. 2b). Using a funnel, the casting took about 7 minutes for each panel. The mean cube compressive strength (100 $\mathrm{mm}$ cubes) was $106 \mathrm{MPa}, 136 \mathrm{MPa}$ and $165 \mathrm{MPa}$ measured 2, 7 and 28 days after casting, respectively.

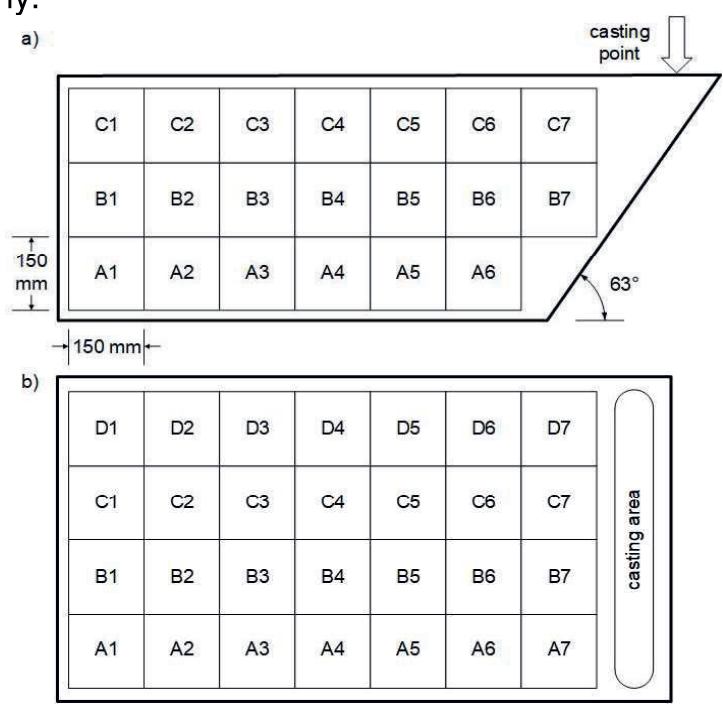

Fig. 2: a) Front view of the vertically casted panels, b) top view of the horizontally casted panel

After hardening, the panels were sawn into square specimens with a side length of
$150 \mathrm{~mm}$ for ultrasonic testing. The specimens were specified according to Fig. 2.

\subsection{Ultrasonic shear wave testing}

For the experiments, a low-frequency shear wave transducer with a centre-frequency of $500 \mathrm{kHz}$ was used in a pulse-echo mode. A crystallised honey was used as coupling medium between the transducer and the UHPFRC specimens. The wave velocities of the generated shear waves were determined via a specially designed measuring system (Ritec-RAM 5000-SNAP), which evaluates analogously the phase spectrum of the received waves.

This method can be explained by assuming two signals $u_{0}$ and $u_{1}$ with different wave velocities according to Eqs. (5) and (6).

$$
\begin{aligned}
& u_{0}=\mathrm{A} \cdot \sin \left(2 \pi f \cdot t_{0}\right)=\mathrm{A} \cdot \sin \left(\varphi_{0}\right) \\
& u_{1}=\mathrm{B} \cdot \sin \left(2 \pi f \cdot t_{1}\right)=\mathrm{B} \cdot \sin \left(\varphi_{1}\right)
\end{aligned}
$$

where

$\begin{array}{ll}f: & \text { excitation frequency } \\ \varphi: & \text { phase angle } \\ t: & \text { time of flight }\end{array}$

By using the path length $D$, the relation between the phase angle $\varphi$ and the wave velocity $v_{0}$ is given for signal $u_{0}$ by Eq. (7).

$t_{0}=\frac{\varphi_{0}}{2 \pi f} \Rightarrow v_{0}=\frac{2 D}{t_{0}}$

In the same way, the wave velocity can be calculated for signal $u_{1}$.

Now, by measuring the corresponding phase difference $\Delta \varphi=\varphi_{0}-\varphi_{1}$ between both signals the relative change in the wave velocity $\Delta v / v_{0}$ can be calculated by Eqs. (8) and (9) respectively.

$$
\begin{aligned}
& \Delta t=t_{0}-t_{1}=\frac{\Delta \varphi}{2 \pi f} \\
& \frac{\Delta v}{v_{0}}=\frac{\Delta t}{t_{0}}
\end{aligned}
$$

Using this method, the shear wave velocities $v_{\mathrm{s}}$ were calculated for different rotation angles. Therefore, the transducer was rotated from a stipulated starting position $\left(\theta=0^{\circ}\right)$ in $15^{\circ}$ increments and the associated relative changes in the wave velocity with respect to the starting position were recorded (Fig. 3). 


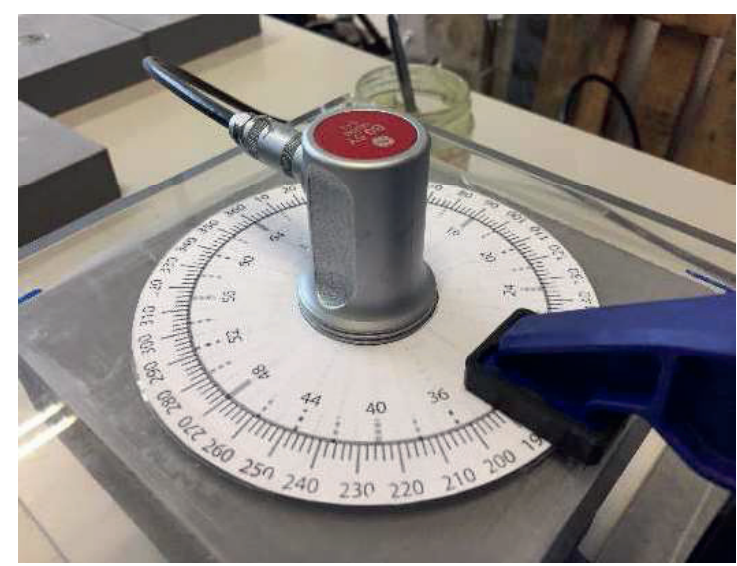

Fig. 3: Experimental setup: Shear wave transducer with a polar disk

Finally, this measurement procedure results in a diagram as given exemplarily in Fig. 4. Here, the percentage change in the shear wave velocity $\Delta v_{\mathrm{s}} / v_{\mathrm{s}, 0}$ is given as a function of the rotation angle $\theta$. Based on this diagram, the maximum wave velocity change and the corresponding rotation angle $\theta_{\max }$ were determined for each specimen. The latter quantity describes the expected predominant fibre alignment at the measuring point. Subsequently, the wave velocity change at the position perpendicular to the maximum wave velocity change was determined $\left(\theta_{90^{\circ}}=\theta_{\max } \pm 90^{\circ}\right)$ and correlated to the maximum value. So the increase of the shear wave velocity starting from the position according to the predominant fibre alignment to the position perpendicular thereto can be described.

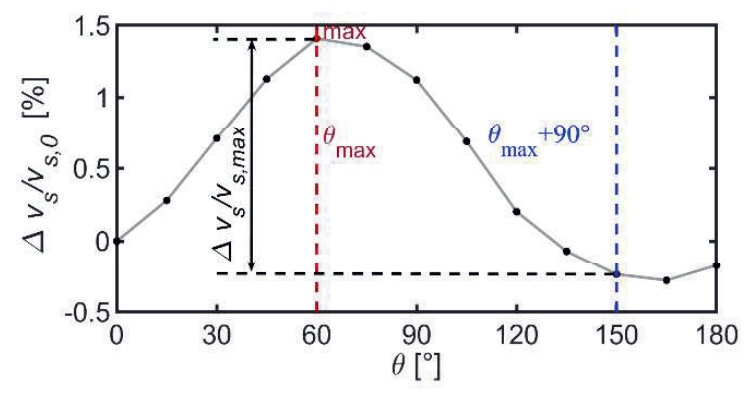

Fig. 4: Percentage change of the shear wave velocity $v_{\mathrm{s}}$ as a function of the rotation angle $\theta$

\subsection{Optoanalytical method}

After ultrasonic testing, specimens with particularly high differences in the relative wave velocities were selected for subsequent analysis of fibre orientation. The objective was to validate the results of the non-destructive ultrasonic measurement by means of a proven test method for evaluating the fibre distribution and orientation. As presented in [20-24], the opto- analytical method has proven to be such a suitable tool.

The square specimens were sawn parallel and perpendicular to the rotation angle $\theta_{\max }$, which was predicted by ultrasonic testing to represent the predominant fibre alignment. By sawing, the steel fibres are melted at the cut surface and show deformed shapes. Thus, the cut sections were polished to recover the real shape of the fibres. After polishing, the crosssections were photographed (Fig. 5) and analysed with the software FiDiOr [22].

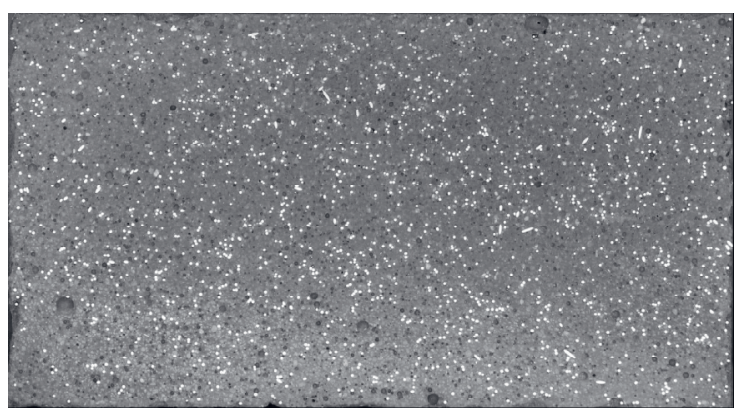

Fig. 5: Detail of a photography of a polished cross-section orientated perpendicular to the predominant fibre alignment

FiDiOr uses the contrast between darker concrete and lighter steel to determine the elliptical shapes of the cut fibres via grey value analysis. This provides number, individual coordinates, long and short principal axis and crosssectional area of the ellipses (= fibres). With these data the inclination of the ellipse's principal axis against the axis of the cross-sectional plane as well as their out-of-plane inclination $\alpha$ can be calculated. Fig. 6 shows the situation and the notations for an inclined fibre in a cut section.

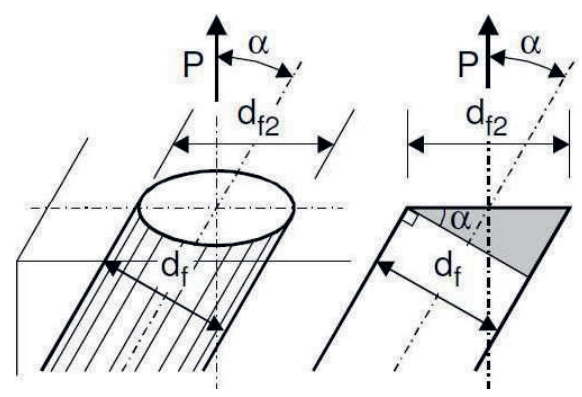

Fig. 6: Inclined fibre in a cut section [23]

For an individual fibre the coefficient of fibre orientation $\eta_{\mathrm{f}, \mathrm{i}}$ can be calculated by Eq. (10).

$\eta_{\mathrm{t}, \mathrm{i}}=\cos \alpha=\frac{d_{\mathrm{f}}}{d_{\mathrm{i} 2, \mathrm{i}}}$ 
where

$d_{f}$ : length of the short principal axis of the elliptical cross-section (= fibre diameter)

$d_{f 2, i}$ : length of the long principal axis of the elliptical cross-section of fibre $i$

After evaluating the individual fibres of a crosssection, the mean coefficient of fibre orientation $\eta_{S}$ in this cross-section can be calculated by Eq. (11) [20-24].

$\eta_{\mathrm{S}}=\frac{1}{N_{\mathrm{f}}} \cdot \sum_{i=1}^{N_{\mathrm{f}}} \eta_{\mathrm{f}, \mathrm{i}}$

where

$N_{\mathrm{f}}$ : $\quad$ number of fibres in the cross-section

However, in order to represent the fibre orientation of a specific volume, the mean coefficient of fibre orientation $\eta_{N}$ is to be calculated by Eq. (12) [24].

$$
\eta_{\mathrm{v}}=\frac{N_{\mathrm{f}}}{\sum_{i=1}^{N_{\mathrm{f}}} \frac{1}{\eta_{\mathrm{f}, \mathrm{i}}}}
$$

Based on $\eta_{N}$, the fibre volume fraction of a specimen can be predicted by Eq. (13) $[20,22,24]$.

$\rho_{\mathrm{f}}=\frac{N_{\mathrm{f}} \cdot \pi \cdot d_{\mathrm{f}}^{2}}{4 \cdot A_{\mathrm{c}} \cdot \eta_{\mathrm{V}}}$

where

$A_{\mathrm{c}}$ : cross-section of the concrete

\section{Results and evaluation}

The results of the ultrasonic and photographic analyses are summarised in Tab. 2.

Tab. 2: Mean coefficient of fibre orientation of the volume, predicted fibre volume fraction, number of fibres and percentage wave velocity change of the selected specimens sawn from panel no. $1,2,3$, and 4

\begin{tabular}{|c|c|c|c|c|c|c|c|}
\hline No. & $\begin{array}{l}\eta N, \max \\
{[-]}\end{array}$ & $\begin{array}{l}\eta_{N, 90^{\circ}} \\
{[-]}\end{array}$ & $\begin{array}{l}\rho_{\max } \\
{[\%]}\end{array}$ & $\begin{array}{l}\rho 90^{\circ} \\
{[\%]}\end{array}$ & $\begin{array}{l}N_{\max } \\
{[-]}\end{array}$ & $\begin{array}{l}N_{90^{\circ}} \\
{[-]}\end{array}$ & $\begin{array}{l}\Delta v_{\mathrm{s}, \max } / v_{\mathrm{s}, 0} \\
{[\%]}\end{array}$ \\
\hline 1_A1 & 0.738 & 0.466 & 2.604 & 2.388 & 4289 & 2484 & 1.948 \\
\hline 1_A6 & 0.709 & 0.475 & 2.502 & 2.534 & 3712 & 2536 & 1.633 \\
\hline 1_B2 & 0.752 & 0.433 & 2.159 & 1.864 & 3734 & 1835 & 1.416 \\
\hline 1_B3 & 0.736 & 0.395 & 2.374 & 1.917 & 4088 & 1772 & 1.658 \\
\hline 1_C1 & 0.802 & 0.363 & 2.069 & 1.840 & 3281 & 1208 & 1.647 \\
\hline 1_C4 & 0.699 & 0.513 & 1.969 & 1.906 & 2685 & 1817 & 1.244 \\
\hline 1_C7 & 0.764 & 0.513 & 2.074 & 1.737 & 3063 & 1620 & 1.562 \\
\hline 2_A1 & 0.746 & 0.497 & 2.363 & 2.006 & 3179 & 1784 & 0.709 \\
\hline 2_A4 & 0.815 & 0.380 & 2.267 & 2.116 & 3321 & 1447 & 0.697 \\
\hline 2_A6 & 0.796 & 0.393 & 2.262 & 1.873 & 3125 & 1287 & 0.849 \\
\hline 2_B1 & 0.746 & 0.439 & 2.236 & 2.017 & 2847 & 1513 & 0.678 \\
\hline 2_C4 & 0.776 & 0.412 & 2.382 & 2.056 & 3182 & 1466 & 0.862 \\
\hline 3_A1 & 0.717 & 0.474 & 2.774 & 2.801 & 4376 & 2991 & 1.253 \\
\hline 3_A3 & 0.712 & 0.454 & 2.573 & 2.476 & 4009 & 2491 & 1.603 \\
\hline 3_A6 & 0.601 & 0.620 & 2.217 & 2.370 & 2920 & 3203 & 1.443 \\
\hline 3_B1 & 0.764 & 0.439 & 2.290 & 2.228 & 3493 & 1976 & 1.585 \\
\hline 3_B7 & 0.709 & 0.407 & 2.347 & 2.137 & 3528 & 1821 & 1.167 \\
\hline 3_C6 & 0.681 & 0.517 & 2.198 & 1.867 & 2956 & 1794 & 1.144 \\
\hline 4_A1 & 0.743 & 0.492 & 2.430 & 2.277 & 4000 & 2540 & 1.102 \\
\hline 4_A2 & 0.754 & 0.436 & 2.611 & 2.112 & 4529 & 2109 & 0.992 \\
\hline 4_A4 & 0.752 & 0.418 & 2.268 & 1.944 & 4066 & 1950 & 0.905 \\
\hline 4_A6 & 0.748 & 0.425 & 2.325 & 2.197 & 4041 & 2170 & 0.938 \\
\hline 4_B1 & 0.787 & 0.375 & 2.342 & 1.835 & 4183 & 1579 & 1.039 \\
\hline 4_C1 & 0.788 & 0.341 & 2.317 & 1.963 & 3528 & 1119 & 1.423 \\
\hline Avg. & 0.743 & 0.445 & 2.331 & 2.103 & 3589 & 1938 & 1.229 \\
\hline CV & $6.14 \%$ & $13.90 \%$ & $8.01 \%$ & $12.54 \%$ & $14.96 \%$ & $27.91 \%$ & $29.29 \%$ \\
\hline
\end{tabular}


The experimental data are subdivided into four groups corresponding to the four panels from which the test specimens were taken from. Panel no. 1, 3, and 4 were cast vertically. Panel no. 2 was cast horizontally.

As already mentioned, the optoanalytical evaluation was performed in two cross-sections perpendicular to each other. For a clear distinction, the cross-section perpendicular to the expected predominant fibre alignment is denoted by the index "max" while the section parallel to the expected predominant fibre alignment is denoted with the index " $90^{\circ}$ ".

The coefficient of fibre orientation $\eta N$, the fibre volume fraction $\rho$ and the number of fibres $N$ obtained by optoanalytical evaluation are listed in Tab. 2 for each specimen. Furthermore, the maximum percentage wave velocity change $\Delta v_{\mathrm{s}, \max } / v_{\mathrm{s}, 0}$ measured by the ultrasonic method is indicated. The average values (Avg.) and the associated coefficients of variation (CV) are presented at the end of the table.

Looking at the fibre volume fraction it is noticeable that the values for individual specimens deviate by up to $20 \%$ from the actual fibre volume fraction of the mixture $(2.5 \%)$. This may be due to sedimentation of the fibres in the fresh concrete.

The wave velocity changes of individual panels deviate in some cases by up to $30 \%$. While panels no. 1 and no. 3 have high velocity change values of 1.24 to $1.95 \%$ and 1.14 to $1.60 \%$, panels no. 2 and no. 4 have much lower values in the range of 0.71 to $0.86 \%$ and 0.91 to $1.44 \%$ respectively. Since visual inspection of the cross-sections showed a significantly increased proportion of air voids for panels no. 2 and no. 4, these air voids might be responsible for a major part of the deviations mentioned before. The air voids can be explained as a result of poor ventilation during casting due to insufficient compaction. In principle, air voids will influence the ultrasonic measurement, depending on their form and distribution in the concrete. Further investigation is required in order to finally explain the observed deviations in velocity changes.

With a value of $\eta_{N \text {,max }}=0.74$ the cross-sections perpendicular to the rotation angle $\theta_{\max }$ on average show a high coefficient of fibre orientation while the average coefficient of fibre orientation is significantly smaller for the crosssections parallel to $\theta_{\max }\left(\eta v, 90^{\circ}=0.44\right)$. Thus, it can be basically stated that ultrasonic measurement is able to identify directions with high coefficient of fibre orientation corresponding to the predominant fibre alignment.

\section{Conclusions and outlook}

In this study, a novel ultrasonic method for determining the fibre orientation in UHPFRC was applied. The evaluation of the results obtained with ultrasonic and optoanalytical method confirms that the method is generally suitable for qualitatively determining the predominant fibre alignment in UHPFRC. However, a quantitative assessment for a specific coefficient of orientation for individual specimens depends on different factors, which may be investigated and evaluated in further studies. The main influencing factors are inhomogeneities, such as air voids, aggregate, etc. as well as heterogeneous fibre distribution in the concrete. Furthermore, the coupling condition between the transducer and the specimen's surface is influencing the ultrasonic measurement.

The present study may be considered as a meaningful starting point for future work in this research field. For example, new ultrasonic methods using air-coupled transducers or surface acoustic wave (SAW) methods can be adopted to overcome some drawbacks of the present method and to automate the measuring procedure.

\section{References}

[1] V.M. Malhotra, J.C. Nicholas, Handbook on nondestructive testing of concrete. Boca Raton, Fla: CRC Press. (2003); doi: $10.1201 / 9781420040050$

[2] M. Krause, M. Bärmann, R. Frielinghaus, F. Kretzschmar, O. Kroggel, K.J. Langenberg, C. Maierhofer, W. Müller, J. Neisecke, M. Schickert, V. Schmitz, H. Wiggenhauser, F. Wollbold, Comparison of pulse-echo methods for testing concrete. NDT \& E International. 30(4), 195-204 (1997); doi: 10.1002/best.200900679

[3] D. Breysse (ed.), Non-destructive assessment of concrete structures: reliability and limits of single and combined techniques. Springer Netherlands. (2012); doi: 10.1007/978-94-0072736-6

[4] G. Washer, P. Fuchs, A. Rezai, H. Ghasemi, Ultrasonic measurement of the elastic properties of ultra-high performance concrete (UHPC). In P.J. Shull, A.L. Gyekenyesi, A.A. Mufti (eds.), Nondestructive Evaluation and Health Monitoring of Aerospace Materials, Composites, and Civil Infrastructure IV. SPIE (2005); doi: $10.1117 / 12.601815$

[5] M. Benaicha, O. Jalbaud, A. Hafidi Alaoui, Y. Burtschell, Correlation between the mechanical behavior and the ultrasonic velocity of fibrereinforced concrete. Construction and Building Materials. 101, 702-709 (2015); doi: 10.1016/j.conbuildmat.2015.10.047

[6] E. Reufi, J. Marku, T. Bier, Ultrasonic pulse velocity investigation of polypropylene and steel fibre reinforced concrete. Zenodo. (2016); doi: 10.5281/zenodo. 1112125 
[7] B.T. Gebretsadik, Ultrasonic pulse velocity investigation of steel fibre reinforced selfcompacted concrete. UNLV Theses, Dissertations, Professional Papers, and Capstones. (2013).

[8] E. Fehling, M. Schmidt, J. Walraven, T. Leutbecher, S. Fröhlich, Ultra-High Performance Concrete UHPC: Fundamentals - Design - Examples. Berlin: Ernst \& Sohn. (2014); doi: 10.1002/9783433604076

[9] T. Leutbecher, E. Fehling, Rissbildung und Zugtragverhalten von mit Fasern verstärktem Stahlbeton am Beispiel ultrahochfesten Betons - Teil 1: Rissmechanische Zusammenhänge. Beton- und Stahlbetonbau. 104(6), 357-367 (2009); doi: 10.1002/best.200900677

[10] T. Leutbecher, E. Fehling, Rissbildung und Zugtragverhalten von mit Fasern verstärktem Stahlbeton am Beispiel ultrahochfesten Betons - Teil 2: Experimentelle Untersuchungen und Anwendungsbeispiele. Beton- und Stahlbetonbau. 104(7), 406-415 (2009); doi: 10.1002/best.200900679

[11] L.F. Maya Duque, B.A. Graybeal, Fiber orientation distribution and tensile mechanical response in UHPFRC. Materials and Structures. 50:55, (2017); doi: 10.1617/s11527-016-0914-5

[12] K. Wille, N.V. Tue, G.J. Parra-Montesinos, Fiber distribution and orientation in UHP-FRC beams and their effect on backward analysis. Materials and Structures. 47(11), 1825-1838 (2014); doi: 10.1617/s11527-013-0153-y

[13] M. Curbach, K. Speck, Versuchstechnische Ermittlung und mathematische Beschreibung der mehraxialen Festigkeit von Ultra-

Hochfestem Beton - Zweiaxiale Druckfestigkeit. Arbeitsbericht zum Forschungsvorhaben CU 37/6-1 der Deutschen Forschungsgemeinschaft (DFG), TU Dresden, (2007)

[14] I. Solodov, K. Pfleiderer, D. Döring, G. Busse, Nondestructive evaluation of anisotropy in composite materials via acoustic birefringence. $R e$ search in Nondestructive Evaluation. 19(3), 129-143 (2008); doi: $10.1080 / 09349840801954223$

[15] S.T. Rakotonarivo, C. Payan, J. Moysan, C. Hochard, Local damage evaluation of a laminate composite plate using ultrasonic birefringence of shear wave. Composites Part B: Engineering. 142, 287-292 (2018); doi: 10.1016/j.compositesb.2018.01.006

[16] J.P. Zhou, J.X. Liu, W.Y. Gao, Z.W. Cui, W.G. Lv, K.X. Wang, Effect of anisotropy on shear wave velocity in wood. Advanced Materials Research. 535-537, 1923-1926 (2012); doi: 10.4028/www.scientific.net/amr.535-537.1923

[17] J.E. White, F.A. Angona, Elastic wave velocities in laminated media. The Journal of the Acoustical Society of America. 27(2), 310-317 (1955); doi: 10.1121/1.1907520

[18] B. Zhou, Y. Uchida, Influence of flowability, casting time and formwork geometry on fiber orientation and mechanical properties of UHPFRC. Cement and Concrete Research. 95, 164177 (2017); doi: 10.1016/j.cemconres.2017.02.017
[19] R. Lovichová, J. Fornůsek, L. Soukupová, J. Valentin, Ultrasound gel as suitable tool for simulation of the fiber orientation in the fiber reinforced concrete. EAN 2016 - 54 $4^{\text {th }}$ International Conference on Experimental Stress Analysis, Srní, CZ. (2016).

[20] H.K. Hilsdorf, W. Brameshuber, R. Kottas, Weiterentwicklung und Optimierung der Materialeigenschaften faserbewehrten Betons und Spritzfaserbetons als Stabilisierungselemente der Felssicherung. Forschungsbericht, Universität Karlsruhe, (1985).

[21] K. Schönlin, Ermittlung der Orientierung, Menge und Verteilung der Fasern in faserbewehrtem Beton. Beton- und Stahlbetonbau. 83(6), 168171 (1988); doi: 10.1002/best.198800280

[22] N.V. Tue, S. Henze, M. Küchler, G. Schenck, K. Wille, Ein optoanalytisches Verfahren zur Bestimmung der Faserverteilung und -orientierung in stahlfaserverstärktem UHFB. Beton- und Stahlbetonbau. 102(10), 674-680 (2007); doi: $10.1002 /$ best.200700568

[23] I. Marković, High-Performance Hybrid-Fibre Concrete: Development and Utilisation. Delft University Press, (2006); http://resolver.tudelft.nl/uuid:44ed51cd-fc274353-ab81-cf8348f52443

[24] P. Hadl, S. Henner, H. Kim, N.V. Tue, Experimental investigations on the scattering in the post cracking tensile behaviour of UHFRC. In E. Fehling, B. Middendorf, J. Thiemicke (eds.), Proceedings of HiPerMat 2016, Kassel, D. (2016); doi: 10.19211/KUP9783737600958 